Supplement of Atmos. Chem. Phys., 22, 917-928, 2022

https://doi.org/10.5194/acp-22-917-2022-supplement

(C) Author(s) 2022. CC BY 4.0 License.

(c) (1)

Supplement of

\title{
Secondary organic aerosol formation from the oxidation of decamethylcyclopentasiloxane at atmospherically relevant OH concentrations
}

Sophia M. Charan et al.

Correspondence to: John H. Seinfeld (seinfeld@caltech.edu)

The copyright of individual parts of the supplement might differ from the article licence. 


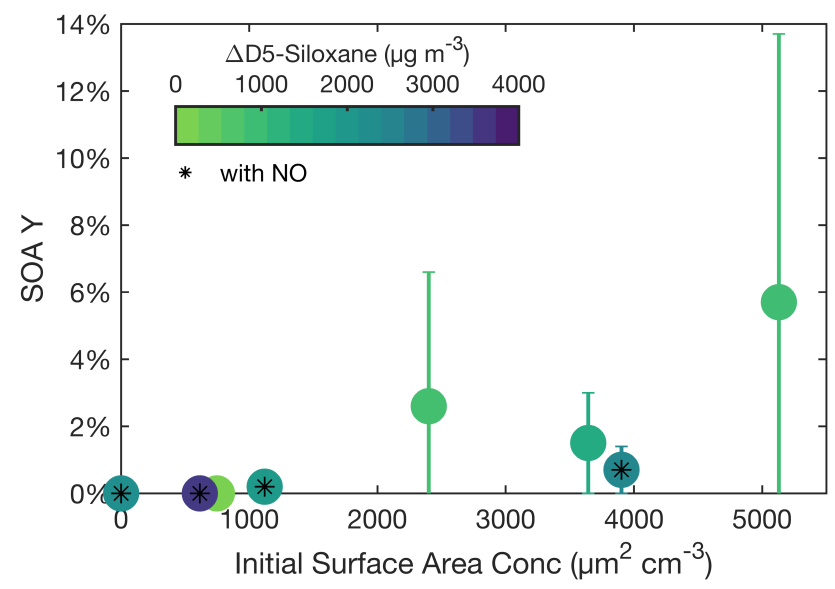

Figure S1. SOA yield at the end of experiments C1-8 with the associated uncertainty is shown as a function of the initial seed surface area concentration. The color of each point represents the amount of D5 that reacted throughout the entire experiment. Experiments with $\mathrm{NO}_{\mathrm{x}}$ present include a black asterisk in their center. 


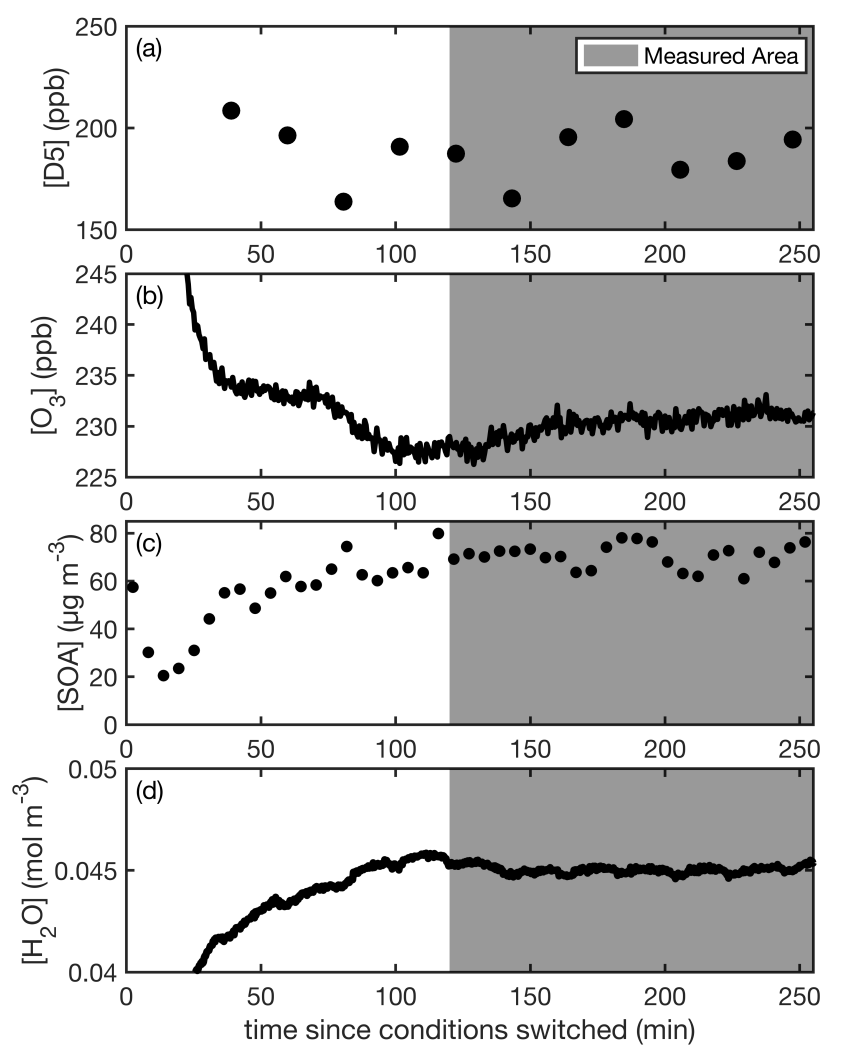

Figure S2. For experiment F11, the stability of the CPOT reactor as shown by measurements at the output of the CPOT of the (a) concentration of D5, (b) concentration of ozone, (c) concentration of SOA, and (d) absolute humidity in the reactor. Data were collected beginning $2 \mathrm{~h}$ after conditions were switched. Data prior to $30 \mathrm{~min}$ are outside the chosen y-axis limits for panels a, b, and d. 


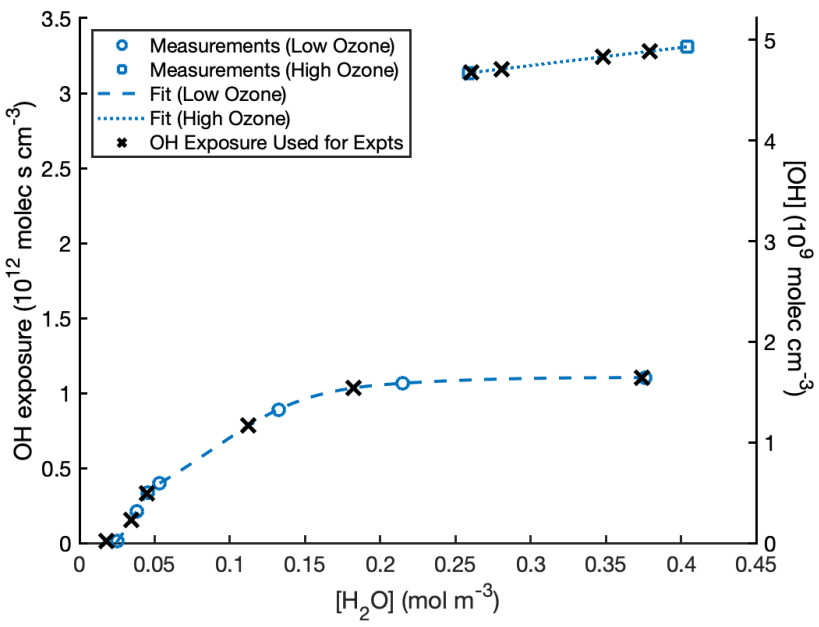

Figure S3. Determination of the $\mathrm{OH}$ exposure and, correspondingly, of the $\mathrm{OH}$ concentration of experiments F9-19. Blue circles and squares are the measurements of the $\mathrm{OH}$ exposure using the reaction of $\mathrm{SO}_{2}$ for the low and high $\mathrm{O}_{3}$ cases, respectively. The dashed and dotted lines are the fits to these measurements and the black Xs are the corresponding OH exposure values used for F9-19. 